\title{
UTILIZAÇÃO DO ÍNDICE DE INCHAMENTO LIVRE PARA DETERMINAÇÃO DA TAXA DE DESSULFURAÇÃO DO PROCESSO DE COQUEIFICAÇÃO*
}

Guilherme Lizeiro Ruggio da Silva ${ }^{1}$ Erick Mitchell Henrique Braga ${ }^{2}$ Lorena Cristina Amorim Moura ${ }^{3}$ lara Patrícia Vieira de Oliveira ${ }^{3}$ Alfredo Carlos Bitarães Quintas ${ }^{3}$

Tamires Miranda Milagres Portilho ${ }^{3}$ Paulo Santos Assis ${ }^{4}$ Natália Brasil Dias ${ }^{3}$

\section{Resumo}

O balanço de enxofre ao longo da cadeia de produção de aço é um problema muito discutido no setor siderúrgico, pois afeta a qualidade do produto final. Assim, este estudo tem como objetivo desenvolver uma metodologia de previsão de enxofre do coque, a partir de enxofre do carvão, com base na sua taxa de dessulfuração, obtida através do Índice de Inchamento Livre (FSI) em escala laboratorial. Estes resultados mostram boa correlação com o processo de fabricação de coque, permitindo a determinação do valor em uso em relação ao teor de $\mathrm{S}$ de cada carvão.

Palavras-chave: carvão mineral, coque, enxofre, dessulfuração, índice de inchamento livre.

\section{Abstract}

\section{USE OF FREE SWEELING INDEX FOR DETERMINING RATE OF} DESULPHURISATION OF COKING PROCESS

The sulfur balance along the steel production chain is much discussed in the steel sector, as it affects the quality of the final product. Thus, this study aims to develop a coke sulfur forecasting methodology, from coal sulfur, based on their rate of desulphurisation achieved through the Free Swelling Index (FSI) in laboratory scale. These results show good correlation with the coking manufacturing process, enabling the determination of the value in use with respect to the $S$ content of each coal.

Keywords: coal, coke, sulfur, desulphurisation, free swelling index.

\footnotetext{
${ }^{1}$ Doutor em Engenharia dos Materiais REDEMAT/UFOP, Gerdau Ouro Branco, Brasil.

${ }^{2}$ Mestre em Engenharia dos Materiais REDEMAT/UFOP, Gerdau Ouro Branco, Brasil

${ }^{3}$ Graduandos em Engenharia Metalúrgica, IFMG Ouro Branco, MG, Brasil

${ }^{4}$ Prof. Dr. Titular da Escola de Minas da UFOP - REDEMAT, Ouro Preto, MG, Brasil
} 


\section{INTRODUÇÃO}

A Siderurgia tem importante papel no ramo industrial brasileiro. Segundo a World Steel, 2016, o Brasil é atualmente o $8^{\circ}$ maior produtor de aço do mundo com 33,3Mt/ano, conforme a Tabela 1 apresenta.

Tabela 1: Produção mundial de aço (WORLD STEEL, 2016).

\begin{tabular}{|c|c|c|c|c|}
\hline \multirow{2}{*}{ Country } & \multicolumn{2}{|c|}{2015} & \multicolumn{2}{|c|}{2014} \\
\hline & Rank & Tonnage & Rank & Tonnage \\
\hline China & 1 & 803.8 & 1 & 822.8 \\
\hline Japan & 2 & 105.2 & 2 & 110.7 \\
\hline India & 3 & 89.4 & 4 & 87.3 \\
\hline United States & 4 & 78.8 & 3 & 88.2 \\
\hline Russia & 5 & 70.9 & 6 & 71.5 \\
\hline South Korea & 6 & 69.7 & 5 & 71.5 \\
\hline Germany & 7 & 42.7 & 7 & 42.9 \\
\hline Brazil ---- & 8 & $33 . \overline{3}$ & $--\overline{9}$ & $-\overline{3} 3 . \overline{9}$ \\
\hline Turkey & 9 & 31.5 & 8 & 34.0 \\
\hline Ukraine & 10 & 23.0 & 10 & 27.2 \\
\hline
\end{tabular}

Atualmente, cerca de $75 \%$ da produção de aço brasileira é oriunda da utilização de ferro gusa, obtido através da redução de minérios-ferro em altos-fornos. Em relação ao volume total de gusa, $80 \%$ é obtido com a utilização de coque como principal combustível dos AF's. Em Minas Gerais temos a maior concentração de Altos-Fornos do Brasil, com $30 \%$ da produção nacional. As maiores produtoras do estado são as usinas integradas a coque da Usiminas, na cidade de Ipatinga e da Gerdau, em Ouro Branco.

\section{Carvão Mineral}

O carvão mineral é o resultado da decomposição de florestas e seres vivos depois de milhões de anos, acompanhados pela atuação da temperatura e pressão referentes às condições geológicas na qual o planeta passou durante o período de sua existência.

Os detritos vegetais provenientes de troncos, raízes, folhas e outras partes das plantas, recobertos em maior ou menor extensão por uma lâmina d'água na bacia de sedimentação, sofreram em maior ou menor grau, ataque biológico. As bactérias e outros microorganismos atacam a celulose e a lignina da madeira, se apoderando do oxigênio, da matéria nitrogenada e do fósforo necessários aos seus desenvolvimentos e subsistências, resultando com isso o que chamamos de Processo de Carbonificação. A Figura 1 a seguir ilustra este fenômeno. 
O TEMPO, A PRESSÃO E A TEMPERATURA
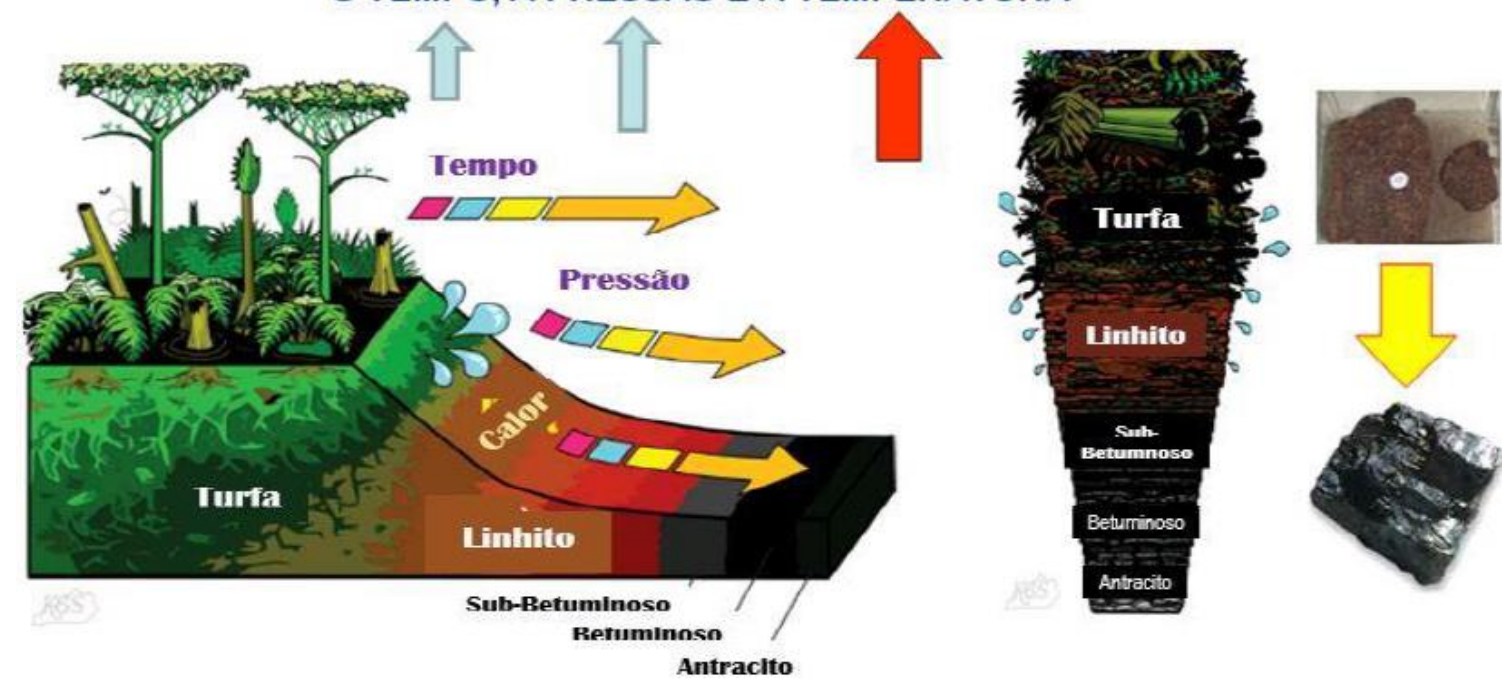

Figura 1: Origem do carvão mineral (ULHÔA, 2003).

A composição química do carvão é variável de acordo com seu grau de evolução e quanto mais avançado o carvão, maior será o teor de carbono na parte orgânica e menor o teor em oxigênio. Os carvões se decompõem, produzindo gases (matéria volátil) e deixam um resíduo aglomerado ou não. Devido ao maior ou menor tempo a que ficou exposta à decomposição, a matéria vegetal dá origem a carvões com diferentes propriedades, evidenciando as fases nas quais passa a matéria orgânica vegetal durante o processo de Carbonificação.

Como o carvão mineral é responsável pela maior parte do enxofre no fluxo de produção do aço, e onera em cerca de 30 a $40 \%$ o custo do mesmo, conhecer o processo de coqueificação se faz cada vez mais necessário para garantir a qualidade do coque com menor custo possível.

A formulação de misturas para coqueificação consiste na definição dos carvões e de suas proporções em cada mistura, para se obter um coque na qualidade desejada, a partir dos carvões disponíveis. A mistura formulada deve atender às condições operacionais do processo de coqueificação e produzir um coque com características de qualidade capaz de desempenhar os papéis dele exigidos no processo de produção de gusa em alto-forno.

A produção de coque no Brasil está inserida num cenário de expressivo declínio das margens de produtos siderúrgicos, onde a maioria das Coquerias Convencionais (fornos verticais, top charching) brasileiras estão em final da vida útil, o que torna ainda mais desafiador a utilização de carvões e materiais alternativos que reduzam o custo da mistura além da mitigação do impacto ambiental causado pelo processo de Coqueificação.

\section{Enxofre no Carvão}

O enxofre contido nas matérias-primas da cadeia de produção do aço é um problema bastante discutido na área siderúrgica, visto que prejudica as propriedades do produto final. A presença do enxofre associado ou não ao oxigênio é uma das principais causas de fragilidade a quente durante o processo de laminação e afeta de forma severa as propriedades de impacto dos produtos.

A redução dos teores de enxofre no alto forno, em pré-tratamento de gusa ou em forno panela, se torna um fator determinante de aumento de custos, o que faz 
com o enxofre seja bem estudado desde o princípio, nas matérias-primas da cadeia produtiva do aço.

O enxofre presente nos carvões se encontra sob a forma de compostos, que se classificam em três grupos: sulfático, pirítico e orgânico. Sabe-se que durante o processo de coqueificação, estes compostos apresentam comportamentos distintos, determinando o índice de dessulfuração da mistura enfornada. (ALVARENGA et. al, 1988). A Figura 2 abaixo traz as formas de enxofre encontradas no carvão mineral.

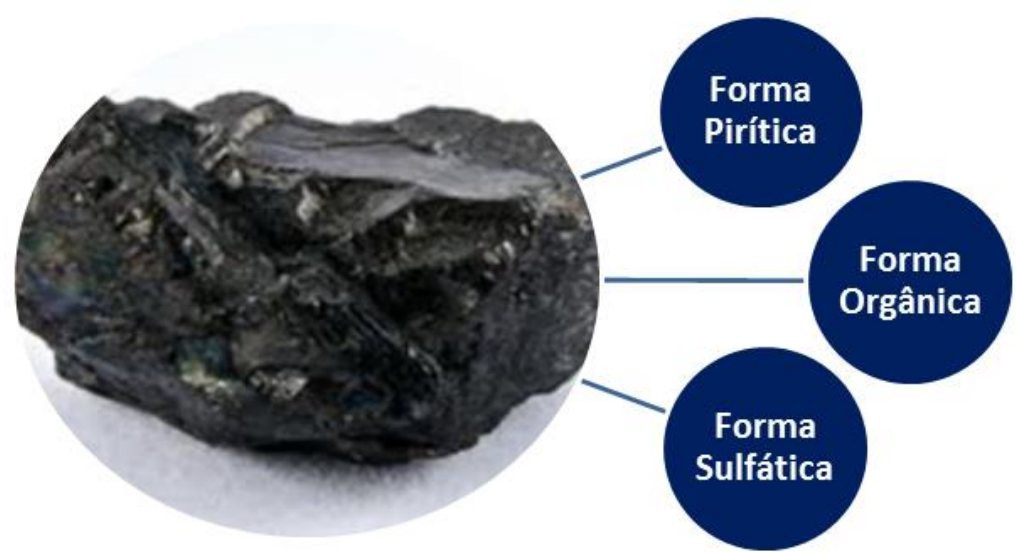

Figura 2: Formas de enxofre no carvão mineral.

Segundo Alvarenga et al (1988), as formas de enxofre no carvão podem ser descritas conforme abaixo:

- Enxofre pirítico:

A forma pirítica engloba o enxofre da pirita e/ou da marcassita, que possuem a mesma formúla, FeS2. Sua remoção ou eliminação é um processo extremamente difícil, pois somente as maiores partículas da pirita poderiam ser removidas do carvão pelos processos convencionais de beneficiamento (ALVARENGA et al., 1988).

- Enxofre orgânico:

O enxofre que está intimamente ligado à molécula do carvão recebe o nome de orgânico. Esta forma não pode ser removida do carvão sem que as ligações químicas que a mantém sejam quebradas. Desse modo, a quantidade de enxofre orgânico do carvão define, teoricamente, o limite máximo de redução do enxofre total que pode ser removido por lavagem. (ALVARENGA et al., 1988).

- Enxofre sulfático:

É a forma de enxofre de menor importância, pois se apresenta nos carvões recém-extraídos, em porcentagens inferiores a 0,05\%. Apenas quando há início de oxidação do carvão, esta proporção tende a aumentar, tendo em vista que parte da pirita se transforma em sulfato (ALVARENGA et al., 1988).

Alvarenga et. al (1988) e Guo et al (2007) apresentaram a decomposição do enxofre no carvão. As Figuras 3 e 4 a seguir trazem tal estudo.

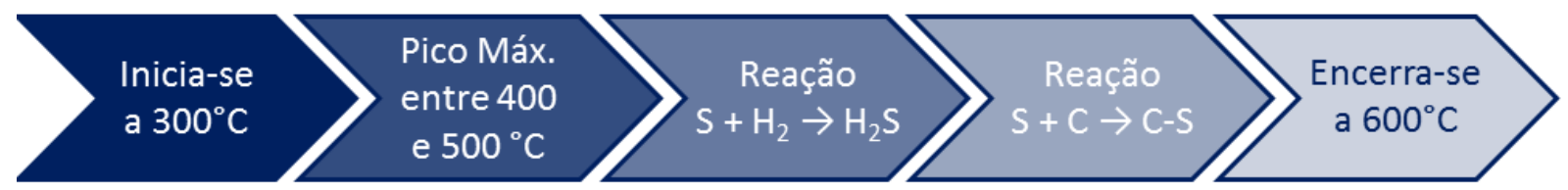

Figura 3: Decomposição do enxofre piritíco (ALVARENGA et al., 1988). 


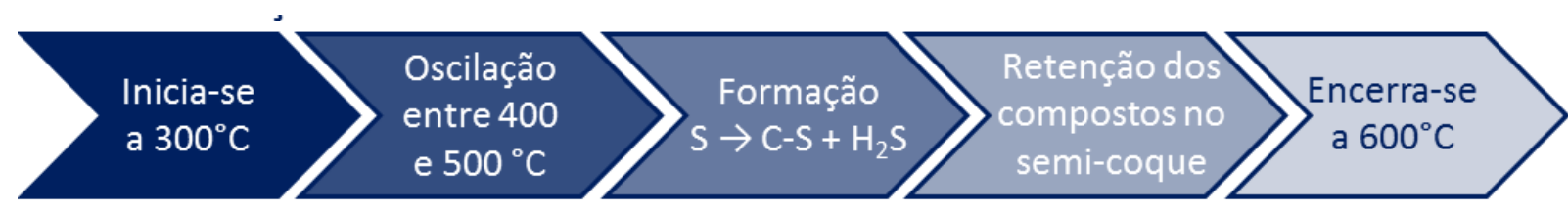

Figura 4: Decomposição do enxofre orgânico (ALVARENGA et al., 1988).

Em 2007, Guo et al estudaram a distribuição de enxofre no coque e a remoção durante o processo de coqueificação e concluíram que o percurso do gás é de vital importância para se explicar as camadas de coque que contém mais enxofre. A Figura 5 abaixo mostra tal percurso.

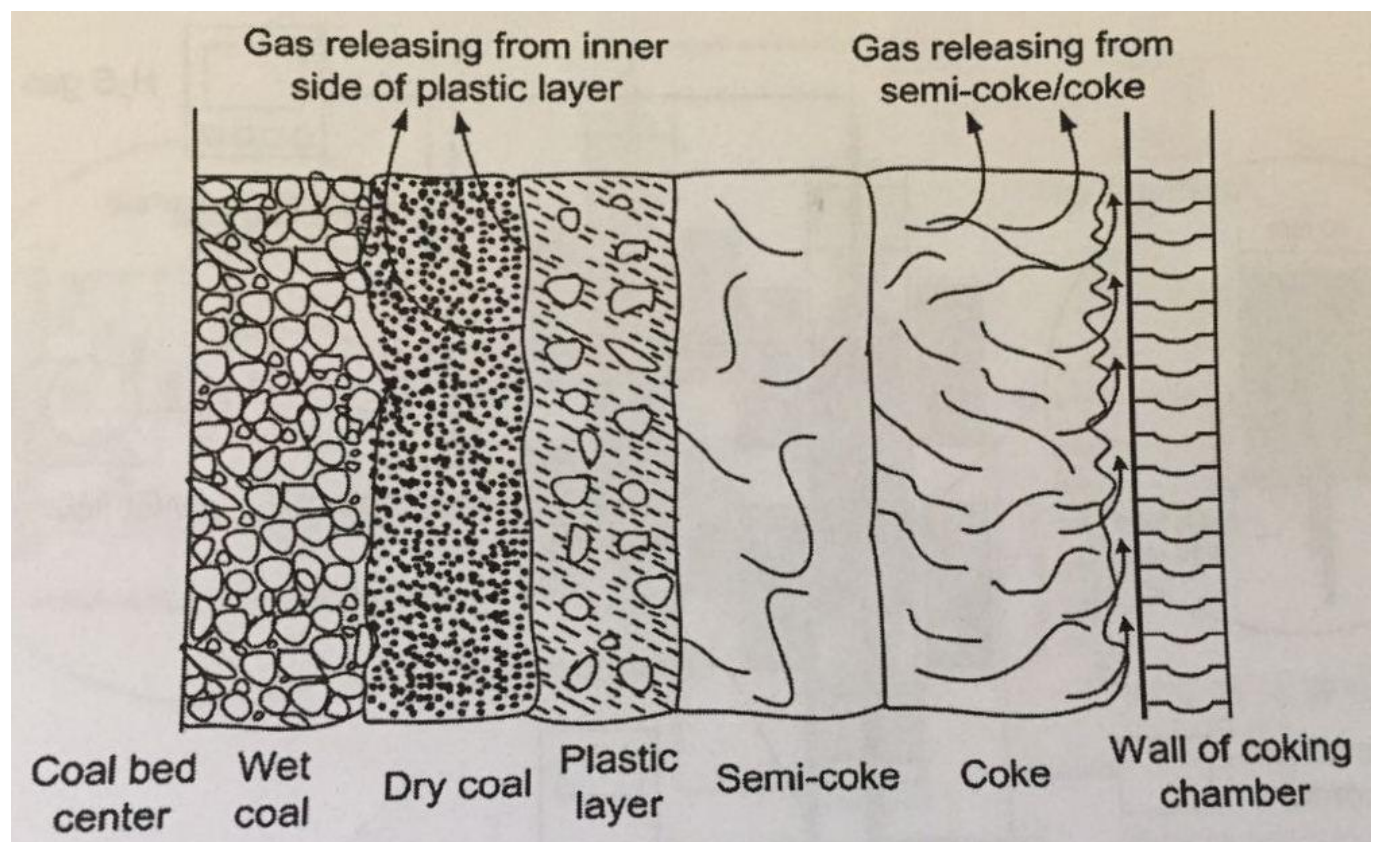

Figura 5: Diagrama do percurso do gás durante processo de coqueificação (GUO et al, 2007).

Durante o processo de coqueificação parte dos gases liberados da camada plástica passam em sentido a parede do forno. Segundo Ulhôa et al (1991) isso acontece devido a maior permeabilidade da massa de semicoque, se comparada com as camadas plásticas do carvão. Apenas uma pequena parte do enxofre contido nos gases retorna ao semicoque sob a forma de complexos C-S. Assim, pôde-se concluir que o teor de enxofre do coque da parede do forno será sempre maior se comparado com o coque do centro.

De acordo com Ulhôa et al (1991), a distribuição do enxofre no coque ao longo da altura do forno, acontece usando-se o mesmo raciocínio. Como o gás da sola do forno, passa pelo carvão até chegar ao topo, o coque gerado no topo do forno possui um teor de enxofre maior se comparada com o coque da sola do forno.

Alvarenga et al (1988) apresentou as reações de remoção de enxofre durante o processo de coqueificação e os percentuais de enxofre do carvão que ficam retidos no coque. A Tabela 2 a seguir mostra tal estudo. 
Tabela 2: Percentual de enxofre no coque após coqueificação (ALVARENGA et al, 1988).

\begin{tabular}{c|c|c} 
FORMA & REAÇÕES & $\%$ S NO COQUE \\
\hline \multirow{2}{*}{ PIRÍtICA } & $\mathrm{FeS}_{2} \rightarrow \mathrm{FeS}+\mathrm{S}$ & \\
& $\mathrm{S}+\mathrm{H}_{2} \rightarrow \mathrm{H} \mathrm{S}$ & $60 \%$ \\
& $\mathrm{~S}+\mathrm{C} \rightarrow$ Complexos C-S & \\
ORGÂNICA & $\mathrm{S} \rightarrow$ Complexos $\mathrm{C}-\mathrm{S}+\mathrm{H}_{2} \mathrm{~S}$ & $60 \%$ \\
SULFÁtICA & $\mathrm{FeS}_{2}\left(\mathrm{SO}_{4}\right)_{3} \rightarrow \mathrm{Fe}_{2} \mathrm{O}_{3}+\mathrm{SO}_{3}$ & $0 \%$
\end{tabular}

O estudo da dessulfuração dos carvões nos proporciona o conhecimento do percentual de enxofre do carvão permanecerá no coque e o percentual que sairá no processo pelo gás de coqueria ou nos produtos líquidos como alcatrão. A Figura 6 abaixo mostra as possíveis saídas do enxofre do carvão.

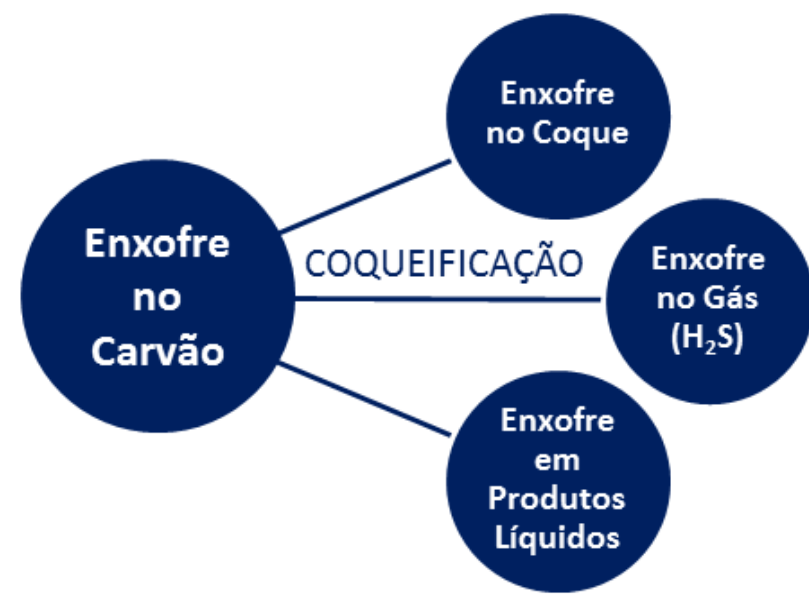

Figura 6: Possíveis saídas de enxofre do carvão.

Conhecendo o processo de dessulfuração dos carvões é possível prever o enxofre do coque, o que faz com que se tenha um maior conhecimento do enxofre do gusa e consequentemente do aço. Atualmente, não há nenhuma forma de se entender tal processo, a não ser por teste de coqueificação em escala piloto, o que torna o conhecimento da taxa de dessulfuração de cada carvão um processo de maior custo e que demanda mais tempo.

A Figura 7 mostra como a taxa de dessulfuração pode ser calculada.

$$
\mathrm{D}-\mathrm{S}=1-\frac{\text { massa de enxofre no coque }}{\text { massa de enxofre na mistura }}=1-\frac{\% \text { enxofre no coque } \mathrm{x} \text { massa de coque }}{\% \text { enxofre na mistura } \mathrm{x} \text { massa de carvão }}
$$

$\frac{\% \text { enxofre no coque } \mathrm{x} \text { massa de coque }}{\% \text { enxofre na mistura } \mathrm{x} \text { massa de carvão }}=$ Rendimento $_{\text {coque/carvão }}$

Rendimento $=99-\frac{5}{6}(\mathrm{MV})$

$\mathrm{D}-\mathrm{S}=1-\frac{\% \text { enxofre no coque }}{\% \text { enxofre na mistura }} \times$ Rendimento $=1-\frac{\% \text { enxofre no coque }}{\% \text { enxofre na mistura }} \times 99-\frac{5}{6}(\mathrm{MV})$

Figura 7: Cálculo da taxa de dessulfuração. 


\section{MATERIAIS E METÓDOS}

Todo o trabalho foi desenvolvido no Laboratório de Matérias-Primas da Usina Siderúrgica Gerdau Ouro Branco. Foram utilizados 5 diferentes carvões fornecidos pela empresa e coque verde de petróleo. A primeira etapa dos experimentos foi a coleta e preparação das matérias primas. Todos os carvões e o PC utilizado apresentavam $85 \%$ das partículas abaixo de $2,83 \mathrm{~mm}$, e foram preparados para 0 ensaio de FSI segundo norma ASTM D70/D720M. A Fig. 8 a seguir esquematiza um resumo do trabalho.

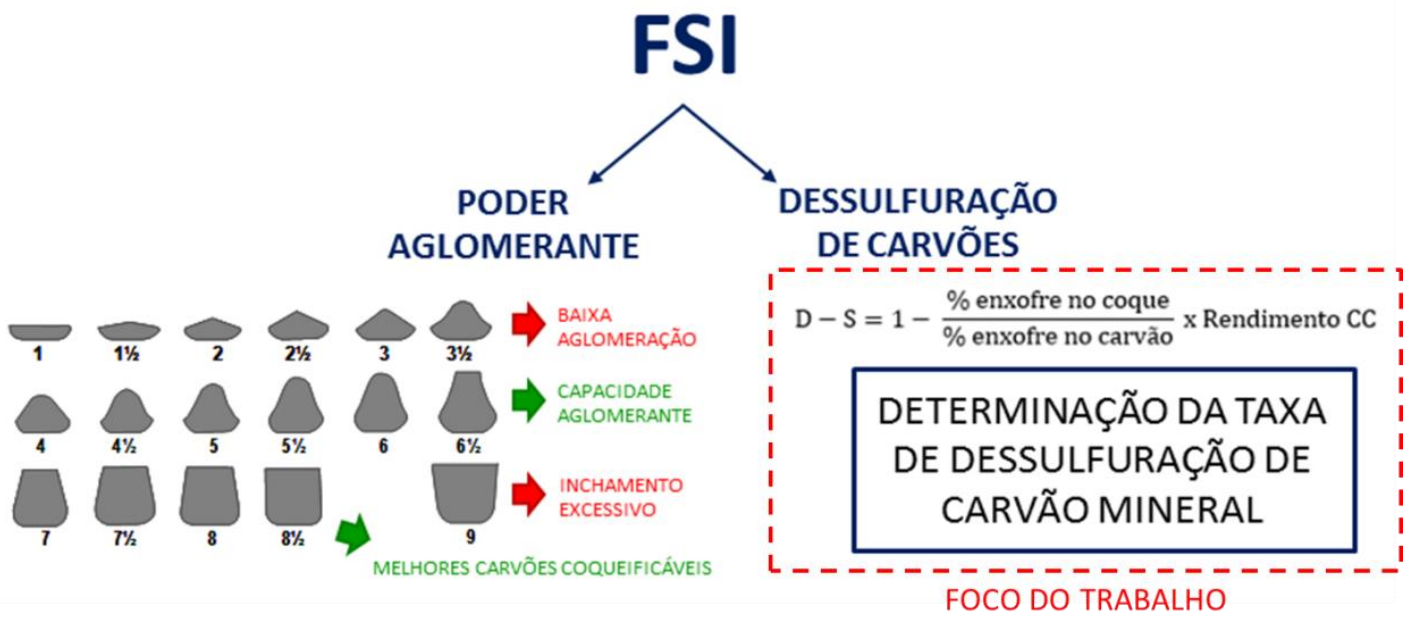

Figura 8: Determinação de D-S a partir de FSI.

Antes de submetidos ao ensaio de $\mathrm{FSI}$, todos os materiais foram analisados quanto à matéria volátil (ASTM D 3175) e teor de enxofre total (ASTM D 3177), para que depois pudesse ser calculada a taxa de dessulfuração. A Fig. 8 abaixo apresenta a norma e descrição do ensaio.

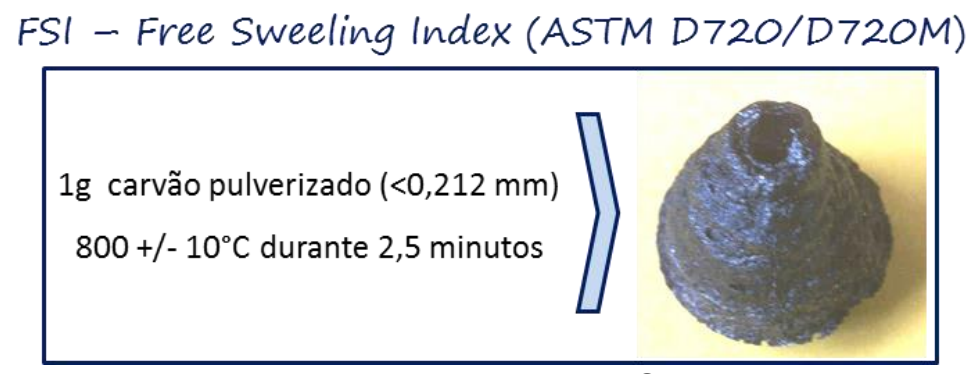

Figura 9: Ensaio de FSI.

\section{RESULTADOS E DISCUSSÃO}

A Tabela 3 abaixo traz os resultados de matéria volátil, enxofre (total e formas) e rendimento de cada material. Com base no teor de voláteis, calcula-se o rendimento (coque/carvão) esperado da seguinte forma:

$$
\text { Rendimento }=99-\frac{5}{6}(\mathrm{VM})
$$


Tabela 3: Teores de enxofre e voláteis, e rendimento de cada material.

\begin{tabular}{c|c|c|c|c|c|c} 
Material & Pirítico (\%) & Orgânico (\%) & Sulfático (\%) & S Total (\%) & MV (\%) & Rend (\%) \\
\hline C1 & 0,51 & 0,16 & 0,02 & 0,70 & 23,21 & 79,58 \\
C2 & 0,23 & 0,78 & 0,00 & 1,01 & 31,16 & 73,03 \\
C3 & 0,24 & 0,66 & 0,04 & 0,93 & 30,57 & 73,53 \\
C4 & 0,23 & 0,40 & 0,02 & 0,64 & 21,65 & 80,96 \\
C5 & 0,21 & 0,11 & 0,01 & 0,33 & 18,76 & 83,37 \\
PC & 0,76 & 0,76 & 0,01 & 0,78 & 10,96 & 89,87
\end{tabular}

Após análise dos materiais e cálculo do rendimento, foi realizado o $\mathrm{FSI}$ e posteriormente, medido o teor de enxofre dos botões formados. Através do enxofre final do botão, foi calculada a taxa de dessulfuração dos materiais. A Table 4 apresenta tais resultados.

Tabela 4: Enxofre dos materiais após FSI.

\begin{tabular}{c|c|c} 
Material & Enxofre pós FSI (\%) & D-S (\%) \\
\hline C1 & 0,64 & 28,35 \\
C2 & 0,6 & 45,98 \\
C3 & 0,5 & 30,53 \\
C4 & 0,7 & 28,40 \\
C5 & 0,4 & 19,43 \\
PC & 0,7 & 22,41
\end{tabular}

Segundo Ulhôa et al (1991), a taxa de dessulfuração tem ligação com o rank. Um carvão alto volátil apresenta maior taxa, enquanto um baixo volátil, apresenta menor. O mesmo pôde ser observado nos resultados obtidos conforme gráfico da Figura 10 abaixo.

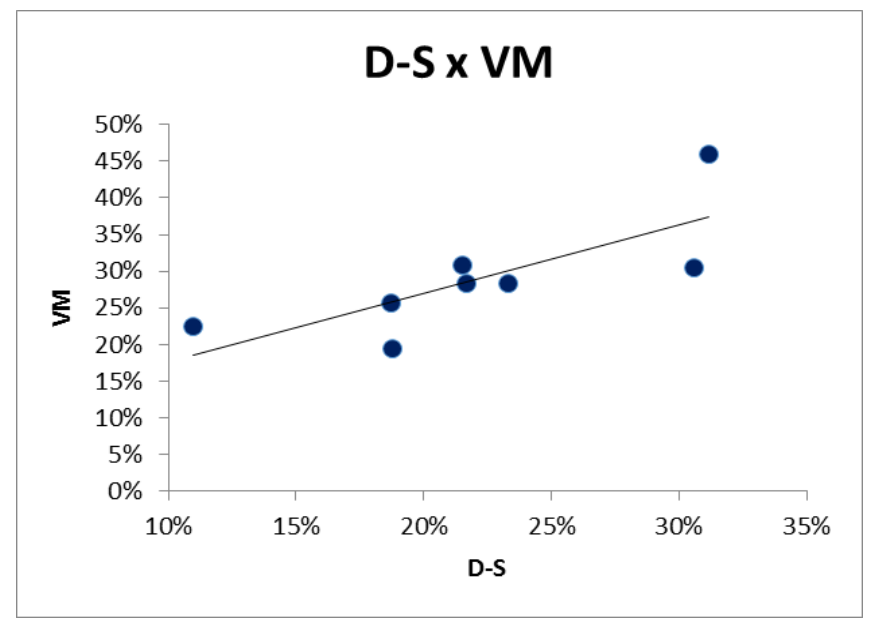

Figura 10: D-S x MV. 
Sabendo-se a taxa de dessulfuração de cada carvão e suas formas e utilizando a ferramenta solver do Excel, podemos definir a dessulfuração de cada forma do carvão, conforme Tabela 5 abaixo. O solver é uma ferramenta que determina um valor máximo ou mínimo de uma célula variando outras. Neste caso, procurou-se minimizar a diferença entre a D-S real e a calculada através das taxas individuais de cada forma de enxofre, variando-se a taxa de cada forma.

Tabela 5: D-S por forma de enxofre.

\begin{tabular}{c|c} 
Pirítico (\%) & 36,41 \\
\hline Orgânico (\%) & 45,37 \\
\hline Sulfático (\%) & 99,98
\end{tabular}

\section{CONCLUSÕES}

- O conhecimento da taxa de dessulfuração dos carvões (D-S) é muito importante pois o enxofre é um elemento que está intimamente ligado ao balanço de qualidade do aço.

- O ensaio de FSI provou ser uma ferramenta muito rápida e prática para determinação da dessulfuração total dos carvões durante processo de coqueificação.

- A taxa de dessulfuração dos carvões, de acordo com a forma do enxofre é de $36,41 \%$ para a forma pirítica, $45,37 \%$ para a orgânica e $99,98 \%$ para a sulfática. 


\section{REFERÊNCIAS}

1. World Steel Association; World Steel in Figures, 2016.

2. Ulhôa, M. B.; Origem e Formação do Carvão. In: Programa de educação continuada. São Paulo: ABM, junho. p10-15; 2003.

3. Alvarenga, E. D.; Silva, L. G.; Silva, J. M.; Jardim, J. C.; O comportamento do enxofre dos carvões durante a coqueificação e as alternativas de dessulfuração. II Seminário Interno de Redução - Açominas, p. 11; 1988.

4. Chiaverini, V.; Aços e Ferro Fundido. Associação Brasileira de Metalurgia e Materiais - ABM; 1998.

5. Guo, Z.; Fu, Z.; Wang, S.; Sulfur distribuition in coke and sulfur removal during pyrolysis. Elsevier; 2007.

6. $\quad$ Tsubouchi, N.; Mochizuki, Y.; Ono, Y.; Uebo, K.; Takanohashi, T.; Sakimoto, N.; Sulfur and Nitrogen Distribuitions during Coal Carbonization snd the Influences of These Elements on Coal Fluidity and Coke Strength. ISIJ International; 2017.

7. Ulhôa, M. B.; Borba, P. E. M.; Conceição, R. A.; Comportamento do enxofre do carvão no processo convencional de coqueificação. Seminário de Fontes Alternativas de Energia para Redução de Minério de Ferro - ABM; 1991.

8. Silva, J. M.; Filho, P. G.; Diminuição do teor de enxofre no coque da Açominas e suas consequências. II Seminário Interno de Redução - Açominas; 1988. 